\title{
Determination of Natural Frequencies of Spur Gear in Portal Axle Gearbox
}

\author{
Devan P D, V.R. Muruganantham
}

\begin{abstract}
Portal axle is introduced to avoid damage of the vehicle bottom portion while it is running on off-road condition by providing additional ground clearance to the vehicle. Since the ground clearance is achieved through gear train arrangement, the operating frequency of the gear shouldn't match with its natural frequency. This work aims to predict the natural frequencies and modes shapes of the gear train with three types of gear arrangements. The effect of natural frequency also studied with three different gear materials such as steel, CI and Al alloy. Gear trains are modeled in Solidworks 2017 and analyzed in well-known FEM software ANSYS workbench 16.0. First six natural frequencies and corresponding mode shapes are also obtained. FEM results are compared with operating frequency of the gear.
\end{abstract}

Keywords - ANSYS Workbench, FEM, Portal axle, Spur Gear, Modal Analysis

\section{INTRODUCTION}

In most four wheel-drive vehicles, the rear wheels are connected by a straight axle tube. But in case of larger wheeled vehicles that carries heavy load would develop more stress on the axle. Especially in off-road vehicle, ground clearance is a major issue since it runs on an uneven pavement. The differential casing of the axle would hit the obstacles which is on the road and gets damaged. To encounter these two issues portal axle is introduced in the off-road military vehicles. Portal axle is having a gearbox at its both ends that allows the wheel axis below the axle tube centerline. Portal axle receives power from the differential unit and sends to the gearbox. Gearbox transfers the power to wheel with appropriate speed reduction if needed. Since the force acting on the gears are distributed, minimal stress will be developed in the axle. At the same time the differential unit gains additional ground clearance and the underneath components are protected from damage. In general, most of the mechanical systems are operated in dynamic loading conditions which results crack, fatigue, noise and vibration. Hence the total working environment get disturbed. Modal analysis is one form of vibration testing method in which the natural frequencies, modal shapes, damping ratios and damping factor of an object can be find out. Most of the heat transfer and mechanical problems are primarily attempted through theoretical method. This method gives an accurate result for simple geometry only. But, the problems are complex and it takes lots of time and cost. An alternate method to solve complex problems with less expensive and time is FEM. Modal analysis can be done in three methods such as experimental

Revised Manuscript Received on July 18, 2019.

Devan P D, Department of Mechanical Engineering, Kumaraguru College of Technology, Coimbatore, Tamil Nadu, India. (E-mail: devan.pd.mec@kct.ac.in)

V.R. Muruganantham, Department of Mechanical Engineering, Kumaraguru College of Technology, Coimbatore, Tamil Nadu, India. test, analytical calculation and FEM analysis. Natural frequencies are inherent properties of an object. Vibration is depending upon mechanical properties and boundary conditions of the structure. Resonance occurs when operating frequency is matches with anyone of the natural frequencies of a structure. ANSYS Workbench software is well known FEM package used to find natural frequencies, mode shapes of a structure.

This work attempts the prediction of natural frequencies of a gearbox on three different spur gear configurations such as gear train having no idler gear, gear train having one idler gear and gear train having two idler gear. Influence of material properties over its natural frequencies are also studied and compared. Steel, Cast Iron are taken as materials.

\section{LITERATURE SURVEY}

Portal axle is a better replacement for normal rear wheel axle in off-road driving environments. It is designed to give more ground clearance to the differential unit. Spur gears are modeled and simulated to find out its dynamic behavior. Modal analysis was carried out on three different combination of gear trains in the gearbox using FEM under both pre-stress and free stress conditions. Through modal analysis resonance characteristics of a structure can be predicted. Mass and stiffness of a system influences the overall dynamic response of a system. First six mode shapes and eight natural frequencies were found. No one natural frequency did match with operating frequency [1]. Modal analysis of mechanical system allows prediction of natural frequencies and corresponding mode shapes. Stiffness of a structure varies according to the load variation. Modal analysis was carried out in impact hammer under different loading conditions with varying mesh stiffness.

Natural frequency increases with increase in load [2]. Ankur Saxena [3] et al have investigated the influence of mesh stiffness on mode shapes and natural frequencies of geared rotor system. Modal analysis involves estimation of modal damping factors, natural frequencies, critical speeds, mode shapes and frequency response functions etc. Over a period, tooth breakage, cracks may develop in gear tooth which alters the mesh stiffness. Isa Yesilyurt [4] et.al have measured the reduction of gear tooth stiffness using modal analysis. Modal analysis also serves to find the damage detection of gear tooth and wear damage. Experiment has been carried out to obtain FRF of the gear tooth. Steel tipped impact hammer used as exciter and accelerometer act as a 
response detector. Peter Weis [5] et.al was aimed to compute first 20 natural frequencies and its corresponding mode shapes of gearbox housing under pre-stressed condition in ANSYS workbench.Ashwani kumar [6] et.al has performed the modal analysis of heavy truck gearbox with four different materials. Gear defects, transmission error and load fluctuations are the foremost cause for vibration. First twenty mode shapes are obtained and better material has been selected. Not only the material properties, the structure of the gear is also influence the natural frequencies. Greater the young's modulus causes greater the natural frequency and life with less noise. It is possible to avoid resonance without modifying properties but by altering structure [7].

In gears, dynamic faults can be diagnosed by two methods such as traditional spectrum analysis and wavelet transform. Fourier Transform is a widely used vibration analyzer. FT can be used at when signal is non-stationary. To overcome this problem by introducing Wavelet Transform. Combination of Time and Frequency domains can be processed in WT [8]. Aditendra Jaiswal et.al have studied different modes of gear failure under dynamic condition using FFT analyzer. Spectrum of a fault in the defective gear is compared with new gear [9]. Dynamic analysis is an efficient method for condition monitoring in day today life. The rise in vibration pattern reveals the defects in rotating components. In vibration analysis acceleration, velocity and displacement are measured based on our choice [10]. Vibration analysis not only used to detect fault, are also used find load fluctuations. Timefrequency domain analysis is an efficient method to diagnose the vibration signals [11].

\section{SELECTION OF GEAR PARAMETERS [12]}

Gear parameters are selected based on the power requirement. Vehicle specification is given in the below table. Gears are designed to the maximum torque value.

TABLE 1 TATRA VEHICLE SPECIFICATIONS

\begin{tabular}{cc}
\hline Vehicle & Tatra T810 \\
Power & $177 \mathrm{KW}$ \\
Max Torque & $820 \mathrm{~N}-\mathrm{m}$ \\
Speed Range & 1220 to $2300 \mathrm{rpm}$ \\
Pay Load & $4500 \mathrm{Kg}$ \\
Ground Clearance & $460 \mathrm{~mm}$ \\
\hline
\end{tabular}

Initially, number of teeth in gear is 20 and pressure angle is $20^{\circ}$ has taken to avoid interference.

$$
\begin{aligned}
& \text { Velocity } \mathrm{V}=\frac{\pi \mathrm{DN}}{60}=\frac{\pi * \mathrm{M} * 20 * 2300}{60}=2.4 \mathrm{M} \mathrm{m} / \mathrm{sec} \\
& \text { Tangential Force } \mathrm{Ft}=\frac{1000 \mathrm{P}}{\mathrm{V}} \mathrm{Cs}=\frac{177 * 1000 * 1.5}{2.4 \mathrm{M}}=\frac{110000}{\mathrm{M}} \mathrm{N} \\
& \mathrm{Ft}=\sigma * \mathrm{CV} * \mathrm{~b} * \mathrm{M} * \mathrm{y} * \pi \\
& \text { Module } \mathrm{M}=6 \mathrm{~mm}
\end{aligned}
$$

All other parameters are calculated based on the module. Both gear and pinion are rotating at the same speed. Hence the speed ratio is 1 . Number of teeth on gear and pinion are equal. Shaft hole diameter has taken as $30 \mathrm{~mm}$ to apply the boundary conditions and load. Involute, full depth spur gear is chosen for analysis.

\section{TABLE 2 GEAR SPECIFICATIONS}

\begin{tabular}{ccc}
\hline Parameters & Formula & Values \\
\hline $\begin{array}{c}\text { Face Width, b }(\mathrm{mm}) \\
\text { Pitch Circle } \\
\text { Diameter, } \mathrm{p}_{\mathrm{c}}(\mathrm{mm})\end{array}$ & $10 \mathrm{M}$ & 60 \\
$\begin{array}{c}\text { Diametrical Pitch, } \\
\mathrm{p}_{\mathrm{d}}\left(\mathrm{mm}^{-1}\right)\end{array}$ & $1 / \mathrm{M}$ & 120 \\
$\begin{array}{c}\text { Addendum, a }(\mathrm{mm}) \\
\text { Dedendum, d }(\mathrm{mm}) \\
\text { Tooth Thickness, } \mathrm{T} \\
(\mathrm{mm})\end{array}$ & $1.5708 \mathrm{M} 2$ & 0.166 \\
$\begin{array}{c}\text { Centre distance, } \mathrm{C} \\
(\mathrm{mm})\end{array}$ & $2 \mathrm{~b}$ & 6 \\
\hline
\end{tabular}

\section{MODELING OF GEAR TRAINS}

All the three gear trains are modeled and assembled in Solidworks 2017 software. Uniform power transmission is ensured between input and output using motion study tool which is inbuilt in the same software. Assembly model of the gear trains are shown in fig. 1
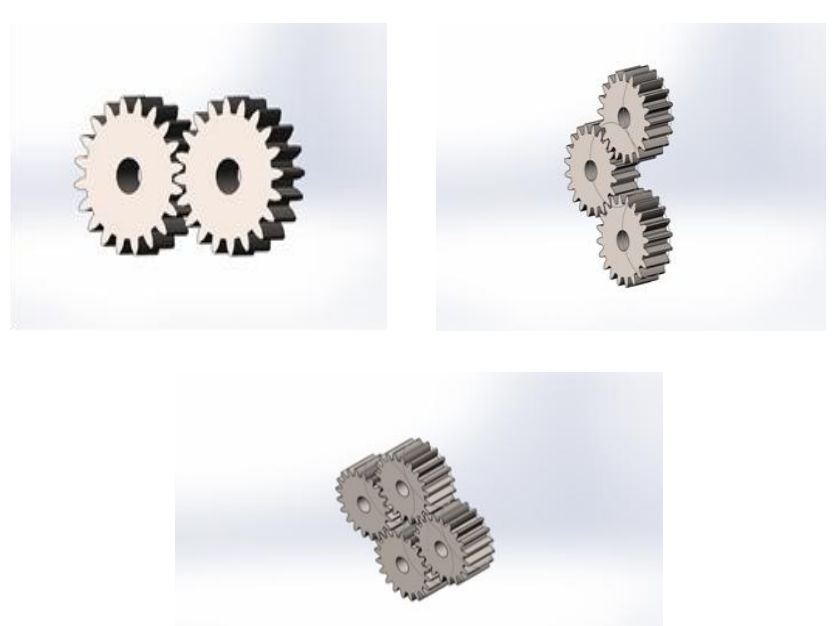

Fig.1. Assembly model of the gear trains

\section{MESHING AND BOUNDARY CONDTIONS}

After importing the gear trains in to ANSYS Workbench, 'tangential constraint' is given to the surfaces of the gears. Input gear is treated as contact and output gear is treated as target. Both are set to 'No separation' contact. In this stage, the corresponding material is also assigned to the gears. All the three gears trains are meshed with tetrahedral element as shown in fig. 2 . 

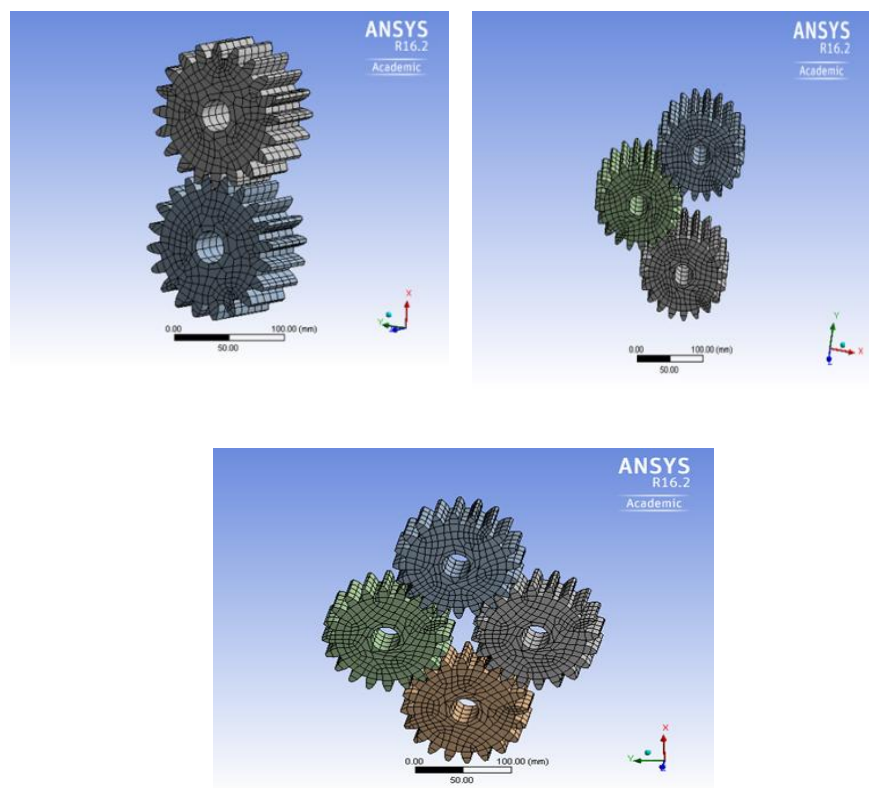

Fig. 2. Meshed view of the gear trains

Boundary conditions are applied at shaft hole free -stress state. Fig.3. shows the constraints applied to the gear trains. In free stress state, fixed support is applied to the gears which doesn't allow any motion.

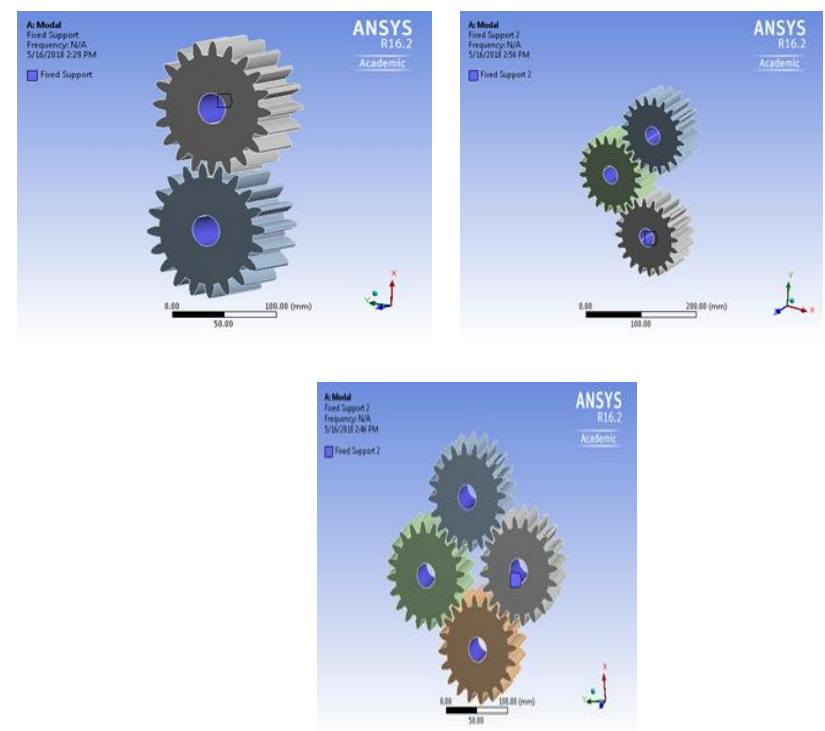

Fig.3. Boundary Condition

\section{MODAL ANALYSIS OF GEARS \& RESULTS}

First four mode shapes and its corresponding natural frequencies are determined in FEM modal analysis. The results are compared with operating frequency.
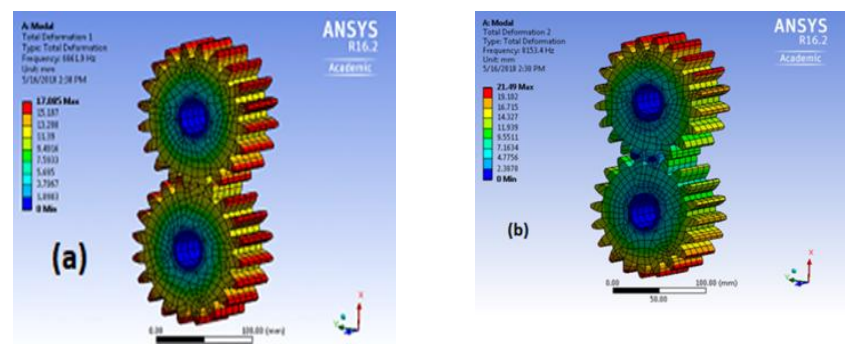
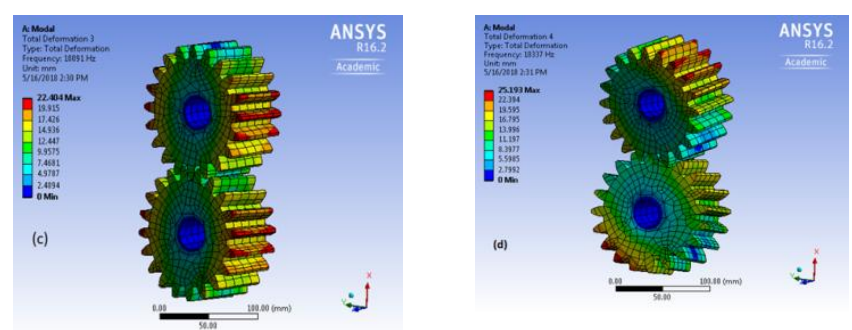

Fig.4. Mode shapes of gear train with no idler gear (Steel)
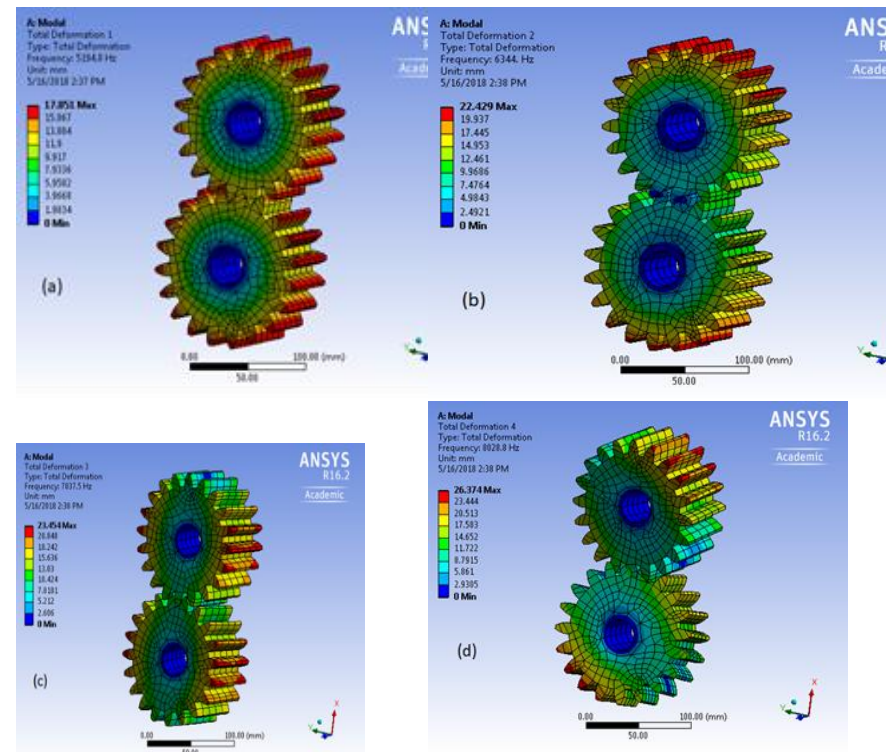

Fig.5. Mode shapes of gear train with no idler gear (CI)

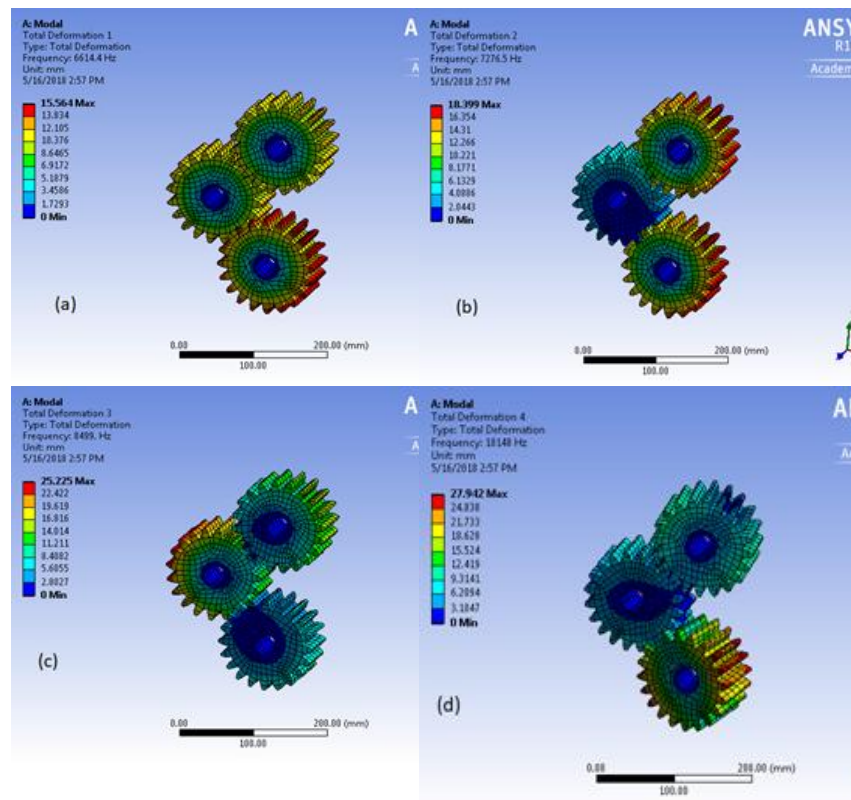

Fig.6. Mode shapes of gear train with one idler gear (Steel)

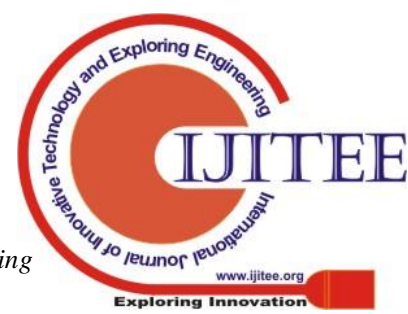



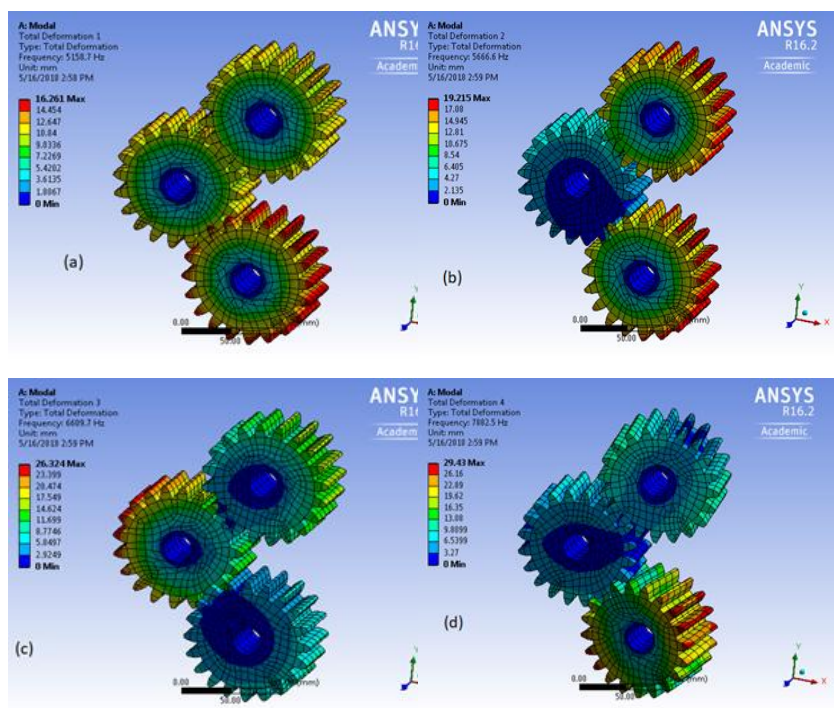

Fig.7. Mode shapes of gear train with one idler gear (CI)
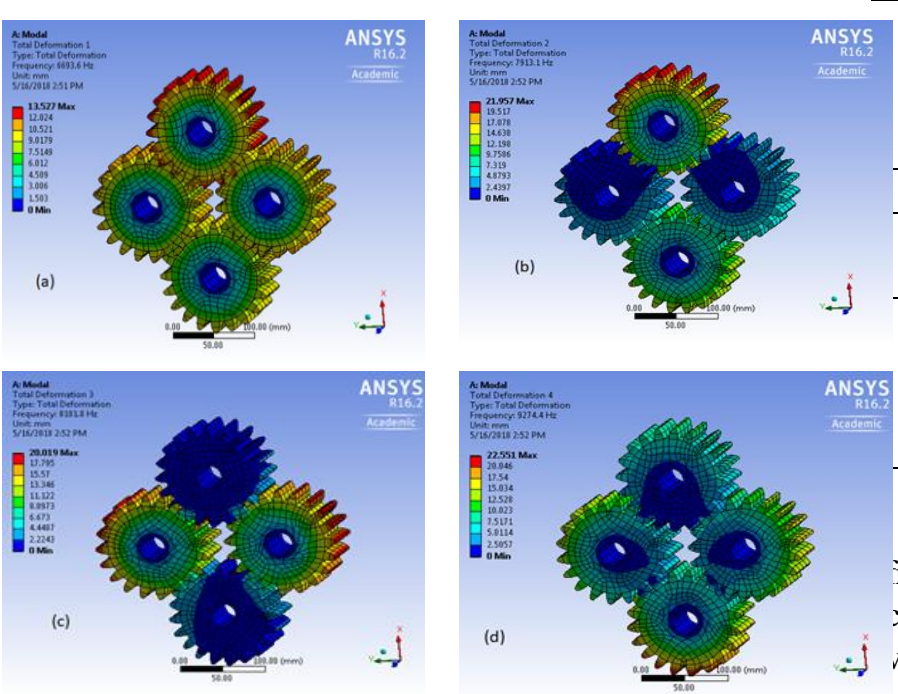

Fig.8. Mode shapes of gear train with two idler gear (Steel)
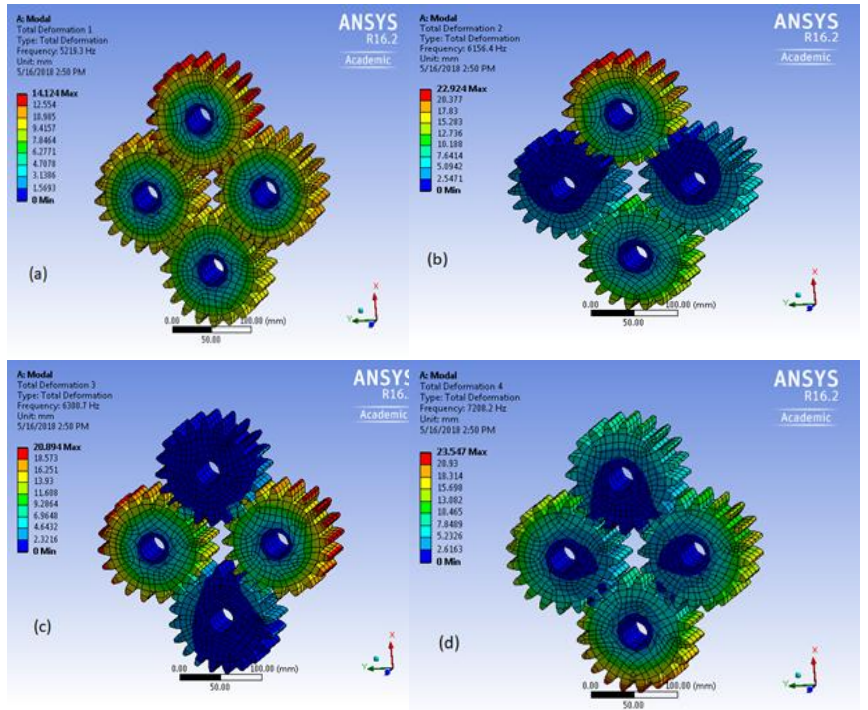

Fig.9. Mode shapes of gear train with two idler gear (CI)
Figure 4,6,8 shows the mode shape of the gear trains having no ideal gear, with one ideal gear and with two ideal gears respectively assigned with steel as material.

Figure 5,7,9 shows the mode shape of the gear trains having no ideal gear, with one ideal gear and with two ideal gears respectively assigned with cast iron as material.

FEM natural frequencies are shown in table 3.

\section{TABLE.3 FEM NATURAL FREQUENCIES}

\begin{tabular}{ccc}
\hline \multicolumn{3}{c}{ Frequency $(\mathrm{Hz})$ for without Idle Gear } \\
Mode & SS & CI \\
\hline 1 & 6661.9 & 5194.8 \\
2 & 8153.4 & 6344.0 \\
3 & 10091.0 & 7837.5 \\
4 & 10337.0 & 8028.8 \\
\hline
\end{tabular}

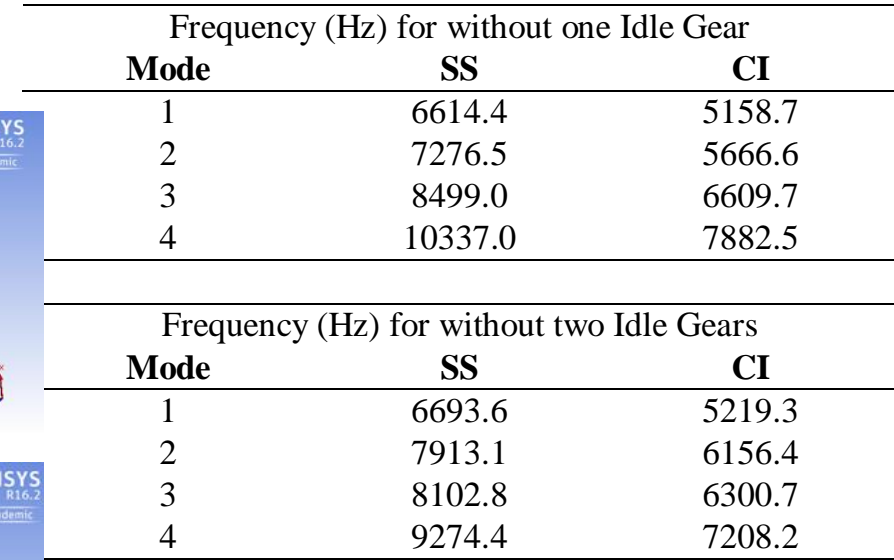

To know the behaviour of gear train at resonance requency, the natural frequencies of the gear train is sompared with operating frequency. Operating speed of the $\therefore$ vehicle is 1200 to $1700 \mathrm{rpm}$.

$$
\begin{gathered}
\mathrm{F}_{\mathrm{n}}=\frac{1}{2 \pi} \omega \\
\omega=\frac{2 \pi N}{60} \\
\mathrm{Fn}=\frac{1}{2 \pi} \frac{2 \pi * 1200}{60}=20 \mathrm{~Hz} \\
\mathrm{Fn}=\frac{1}{2 \pi} \frac{2 \pi * 1700}{60}=28.33 \mathrm{~Hz}
\end{gathered}
$$

The range of operating frequency is in between $20 \mathrm{~Hz}$ to $30 \mathrm{~Hz}$ approximately. This range is very small when compared with lowest natural frequency of $5158 \mathrm{~Hz}$. Hence FEM reveals that resonance will not take place on any gear train and the design is safe for both the materials.

\section{CONCLUSION}

Modal analysis on three spur gear trains of the portal axle gearbox was performed using FEM simulation under freestress state. All gear trains have similar resonance frequency behavior when plotted against the first four mode shapes. There is a huge difference between the natural frequencies of the gear train when compared to operating frequency. 
Hence resonance will not arise with in this operating speed. It can be concluded that, gear train with Cast Iron material undergoes less frequency compared to Steel material.

\section{REFERENCES}

1. Ooi J, Wang X, Tan C, Ho JH, Lim YP. Modal and stress analysis of gear train design in portal axle using finite element modeling and simulation. Journal of Mechanical Science and Technology. 2012 Feb 1;26(2):575-89.

2. Mbarek A, Hammami A, Del Rincon AF, Chaari F, Rueda FV, Haddar M. Effect of load and meshing stiffness variation on modal properties of planetary gear. Applied Acoustics. 2017 Aug 18.

3. Saxena A, Chouksey M, Parey A. Effect of mesh stiffness of healthy and cracked gear tooth on modal and frequency response characteristics of geared rotor system. Mechanism and Machine Theory. 2017 Jan 1;107:261-73.

4. Yesilyurt I, Gu F, Ball AD. Gear tooth stiffness reduction measurement using modal analysis and its use in wear fault severity assessment of spur gears. NDT \& E International. 2003 Jul 1;36(5):357-72.

5. Weis $P$, Kučera L', Pecháč $P$, Močilan M. Modal Analysis of Gearbox Housing with Applied Load. Procedia engineering. 2017 Jan 1;192:953-8.

6. Kumar A, Patil PP. Modal Analysis of Heavy Vehicle Truck Transmission Gearbox Housing Made From DifferentMaterials. Journal of Engineering Science and Technology. 2016 Feb 1;11(2):252-66.

7. Niu S. Modal Analysis of Cylindrical Gear Based on Finite Element Model. system.;2(1):3.

8. Vernekar K, Kumar H, Gangadharan KV. Gear fault detection using vibration analysis and continuous wavelet transform. Procedia Materials Science. 2014 Sep;5:1846-52.

9. Jaiswal A, Zakiuddin KS, Shukla VV. Fault Diagnosis of Gear by Vibration Analysis. International Journal of Latest Trends in Engineering and Technology (IJLTET). 2013 Sep;3(1):26-32.

10. Diwakar G, Satyanarayana MR, Kumar PR. Detection of Gear fault using vibration analysis. International Journal of Emerging Technology and Advanced Engineering, ISSN 2012 Sep:2250-459.

11. Shahapurkar SS, Pansare HS, Dhebe PP, Wagh CS, Desale A. Detection of Fault in Gearbox System Using Vibration Analysis Method.

12. Devan PD, Senthilkumar KM, Arun KK. Investigation on Static Stress Analysis of Portal Axle Gearbox. International Journal of Applied Engineering Research. 2018;13(7):524450. 